\title{
Online mental health communities, self-efficacy and transition to further support
}

DOI:

10.1108/MHRJ-12-2019-0048

\section{Document Version}

Accepted author manuscript

Link to publication record in Manchester Research Explorer

\section{Citation for published version (APA):}

Prescott, J., Rathbone, A., \& Hanley, T. (2020). Online mental health communities, self-efficacy and transition to further support. Mental Health Review Journal, 25(4), 329-344. https://doi.org/10.1108/MHRJ-12-2019-0048

\section{Published in:}

Mental Health Review Journal

\section{Citing this paper}

Please note that where the full-text provided on Manchester Research Explorer is the Author Accepted Manuscript or Proof version this may differ from the final Published version. If citing, it is advised that you check and use the publisher's definitive version.

\section{General rights}

Copyright and moral rights for the publications made accessible in the Research Explorer are retained by the authors and/or other copyright owners and it is a condition of accessing publications that users recognise and abide by the legal requirements associated with these rights.

\section{Takedown policy}

If you believe that this document breaches copyright please refer to the University of Manchester's Takedown Procedures [http://man.ac.uk/04Y6Bo] or contact uml.scholarlycommunications@manchester.ac.uk providing relevant details, so we can investigate your claim.

\section{OPEN ACCESS}




\section{Online Mental Health Communities, Self-Efficacy and Transition to Further Support}

Dr Julie Prescott

Department of Education \& Psychology, University of Bolton, Greater Manchester, England j.prescott@bolton.ac.uk

Amy Leigh Rathbone BSc (Hons)

Department of Education \& Psychology, University of Bolton, Greater Manchester, England alr3wss@bolton.ac.uk

Dr Terry Hanley

Manchester Institute of Education/School of Environment, Education and Development, The University of Manchester, Manchester, England

Terry.Hanley@manchester.ac.uk 


\section{Abstract}

Purpose: $\quad$ This study is exploratory research which aims to understand how users gain support from the online mental health community and whether engagement with said community may possibly lead to increased self-efficacy.

Methodology: 128 users of an online mental health community (OMHC),18percent, completed an online questionnaire that asked open ended questions about the community and how users engaged with it. The results were analysed using quantitative and qualitative methods.

Findings: $\quad$ Based on the construct of self-efficacy within Social Cognitive Theory, it is evident that the platform provides users with increased self-efficacy and encourages further support seeking in a professional capacity, either via an online or offline platform.

Originality: OMHCs provide a therapeutic, peer to peer space for users in times of crisis which have the possibility to increase self-efficacy when engaged with. However, users must acknowledge that although the online platform is an efficacious resource, it cannot be utilised as a principal proxy for offline treatment.

Keywords: online; mental health; community; self-efficacy; support

\section{Introduction}

\section{Mental Health Online}

The use of technology for data acquisition has become a norm. The online platform is now somewhat ubiquitous and has facilitated access to a multitudinous extent of information sources, for both professionals and laities alike (Rathbone \& Prescott, 2017). Via the online platform, information can be assimilated through various means, such as; online search engines, media outlets, academic resources, or social media platforms. Regardless of the method used, there are few barriers regarding topicality, allowing any user with access to the relevant technology, instantaneous retrieval. The global prevalence of mental health and neurological disorders is estimated as affecting one in every four people, making such conditions globally endemic and the principal cause of ill health (WHO, 2001; Newton \& Fitzpatrick, 2018).

Mental health issues, symptomology and diagnoses are heterogeneous; however, all have the propensity to negatively affect wellbeing and decrease quality of life. Reports which estimate the true global prevalence of mental health issues, using an array of population-representative samples substantiate that not only is pervasiveness increasing, but also, that the experience of mental health issues is much more commonplace than originally thought (Saxena, Funk \& Chisholm, 2013; Vos et al, 2015). Emergent lifetime data are showing that the experience of a mental health issues within the life course has become somewhat universal (Schaefer et al, 2017). This has subsequently increased the burden on mental health care settings, resources 
and professionals. Not only is mental health care one of the greatest economic burdens (Stephens \& Joubert, 2001; Trautmann, Rehm \& Wittchen, 2016; Doran \& Kinchin, 2019), but excessive use of services results in extensive time spent on waiting lists, which can have pejorative side effects on patients (Steinmann, Shoben, Dembe \& Kelleher, 2015; Priester et al, 2016).

\section{Online Help Seeking}

The online platform is a beneficial resource for those experiencing mental health issues and comprises of numerous provisions for self-regulation of one's personal mental health (McCosker, 2018). Online platforms offer accessibility to symptom checkers (Yu et al, 2019), counselling (March et al, 2018; Schlenk, 2018), peer-to-peer support (Prescott et al, 2017; 2018; Hanley et al, 2019) social media support groups (Radovic, Landsittel, Stein \& Miller, 2019) and chatrooms (Kiyimba \& Lester, 2019), amongst many others. Due to increased utilisation of health care settings and the ease of access which online platforms facilitate, clinicians and academics alike extensively explore the efficacy of e-health as a mental health intervention (Rathbone \& Prescott, 2017; Rathbone, Clarry \& Prescott, 2017). Previous studies have trialled various interventions using the internet. Some aimed to reduce waiting times for access using methods such as internet-based self-help (Vollert et al, 2019) and econsults (Poulin et al, 2018). Others have used the online platform to deliver talking therapies, which usually take place face to face, such as cognitive behavioural therapy (CBT; Karyotaki et al, 2018; Kallestad et al, 2018). Others provide information such as psychoeducation and methods of engagement with self-help (Weekly, Walker, Beck, Akers \& Weaver, 2018). Overall, as a method of mental health care deliverance, e-health has proven efficacious (Bakker, Kazantzis, Rickwood \& Rickard, 2016; Rathbone \& Prescott, 2017) and can be a valid source of reassurance (Prescott \& Mackie, 2017).

\section{Online Mental Health Communities (OMHC)}

One such resource available are online mental health communities (OMHC). An OMHC is a chat room, where users can relay, communicate and discuss information or personal experiences regarding their mental health. These communities are often solely user led and are a favoured method of support seeking as they circumvent barriers by facilitating an informal but informative community, being freely accessible to all and offering a safe space to find objective parties to confer with (Gray et al, 2014; De Choudry \& De, 2014; Park, Conway \& Chen, 2018; Yang, Kraut, Smith, Mayfield \& Jurafsky, 2019).

Qualitative analysis, carried out by Giles and Newbold (2011), unearthed divergent sentiments within OMHCs. Some users turn to OMHCs as they experience a sense of opposition to treatment delivered via the offline platform and regarded mental health care professionals pejoratively. However, this premise was opposed by data which evidenced users replying to others who were seeking information and support with recurrent prompting to "seek (professional) help," and disclaimers ("I'm not a psychologist"). The authors suggested that this conflict indicates an enduring reverence for skilled professionals.

One American study sought to understand which websites were shared within online OMHCs, by whom and in what context. The authors aimed to explore the practical 
applications of website sharing practice within OMHCs. The study found that $86 \%$ of the websites shared contained relevant health information and 50\% were government owned or certified health websites. One recommendation from this study was that health care practitioners encourage patients to become more informed by providing further information and insight into certified websites via recommendation and redirection (Nath, Adupa \& Jonnalagadda, 2016).

In a UK study, Prescott, Hanley \& Ujhelyi (2019) explored why young people use online forums for mental health and emotional support. Qualitative analysis found that OMHCs are an invaluable resource for users to turn to when they seek peer-to-peer support. They also concluded that moderated online spaces can be beneficial to users as they provide a lower level of support for those in need, however, they do not replace the role of a counsellor.

\section{Self-Efficacy and OMHC}

Social Cognitive Theory (SCT) suggests that behaviours are altered due to personal, behavioural and environmental factors (McAlister, Perry, \& Parcel, 2008). An individual will consider outcomes based on their personal beliefs, social expectations, self-evaluation expectation and self-efficacy (McAlister et al., 2008). Self-efficacy is an individual's belief in their capability of engaging in specific behaviour (Bandura, 1998). Self-efficacy has become the principal foci when applying SCT for health behaviour change (Naslund et al, 2017).

Four behavioural mechanisms of SCT can be implemented to elevate levels of self-efficacy (Naslund et al, 2017). Firstly, mastery of experience allows individuals to undertake small challenges, initially easily mastered, which increasingly become more trying and enhance self-efficacy incrementally through each completion. Secondly, social modelling allows for individuals to engage in a mutual knowledge transfer with others, observing behaviours and encouraging others to observe their sustained achievements. Thirdly, improving physical and emotional circumstances results in increased self-efficacy and finally verbal/social persuasion promotes increased self-efficacy when encouraging others.

These four behavioural mechanisms can be applied to behaviours evidenced when engaging with OMHCs. Mastery of experience relates to the general use of OMHCs. Such small, achievable goals are applicable to the initial introduction to an OMHC, then feeling more confident and engaging in communication with other users and finally, being assured enough to disclose personal mental health issues. The behaviour of social modelling is utilised when communicating with other users online. Improving physical and emotional circumstances occurs when a user implements suggestions from their cohorts and experienced increased wellbeing due to OMHC use and finally verbal/social persuasion is instigated when a user proffers their suggestions in return.

\section{Rationale}

Online health information seeking via the online platform has increased exponentially within the past decade (Prestin, Vieux \& Chou, 2015; Jacobs, Amuta \& Jeon, 2017). OMHCs provide instantaneous support for many people with mental health and emotional needs. The transition to increased online support for mental health needs necessitates further research 
and, in this paper, we explore user experiences of OMHCs, exploring the benefits and efficacy of the community.

Previous research has evidenced that online support such can provide a much-needed sense of community, challenge stigma, and provide access to, and knowledge of, interventions for mental health support (Naslund, Aschbrenner, Marsch \& Bartels, 2016). Users can participate in a shared understanding and discourse regarding their mental health issues with others (Moore \& Ayers, 2017) in a safe online space. Users can engage in informational and emotional, directional or non-directional knowledge transfer (Prescott et al, 2017). Much of the research around online mental health support has focussed on professionally moderated sites, however, this study will consider how users engage with an OMHC that is moderated by non-professional volunteers rather than health professionals.

Autonomous increase in self-efficacy via the medium of OMHC is another focus of the current research. There is a paucity of research which explores the role non-professionally moderated OMHCs may possibly have on self-efficacy. This paper will consider the personal narrative of OMHC users, alongside the four behavioural mechanisms of SCT to understand the support provided to users in terms of why they use the OMHC and the benefits gained, with a focus on how the OMHC can modify levels of self-efficacy.

\section{$\underline{\text { Research Questions }}$}

Applying an SCT framework to understand usage and benefits of the OMHC, 18percent, this research was exploratory in nature and considered the following two research questions;

RQ1: How do users gain support from the OMHC?

RQ2: Does engagement with the OMHC suggest increased self-efficacy?

\section{Method}

\section{Design}

This study used a multi methods design in which both quantitative and qualitative data was collected at the same time through one online questionnaire. Both quantitative and qualitative data were retrieved from an American based global online OMHC known as 18percent. 18percent is a free, peer- to-peer OMHC for those living with mental health issues. The community is based in America but has a global reach. The forum consists of numerous "channels" which are each specific to mental health issue.

Users are directed to the relevant channels by moderators. The role of the moderator within the OMHC is to instigate and engage in topical discussion whilst simultaneously protecting users from content which may be deemed distressing. This is achieved by flagging and removing any comments which may breach the community guidelines and/or have a detrimental effect on user's mental health. Moderators ensure the community members adhere to the code of conduct by adding trigger warnings to posts and removing potential trolls. Moderation is carried out by volunteers who are not mental health professionals, but 
people who are involved in the online community, and who have experienced mental health issues personally. The ethos of the organisation is, "18percent's goal is for members to learn from valuable resources, make long lasting friendships, and share their story. We aspire to be the largest online community for people struggling with mental illness, with a long-term mission to end the stigma of mental illness" (18percent, 2019).

\section{Recruitment}

The authors worked in conjunction with the co-founders of 18percent to design the questionnaire and they emailed users with information about the study and questionnaire link.

\section{Participants}

There were 128 participants. Participants were predominantly female $(68 \%, \mathrm{~N} 88), 27.3 \%$ (N $35)$ were male and $4.7 \%(\mathrm{~N} 6)$ were non-binary. Over half of the participants were between the ages of $16-35(68.7 \%) ; 39.8 \%$ were aged $16-24(\mathrm{~N} 51)$ and $28.9 \%$ were aged $25-35(\mathrm{~N}$ 27). There were 11 participants aged under $16(8.6 \%), 10$ aged 36-46 (7.8\%), 13 aged 47-57 $(10.2 \%)$ and 6 over the aged of 57 (4.7\%). 44.5\% (N 57/128) of participants had been members of 18percent for 0-3 months, 35.2\% ( $\mathrm{N} 45$ ) for 4-7 months and 20.3\% (N 26/128) for over 7 months.

\section{Questionnaire}

The authors worked in collaboration with 18percent to devise a short online questionnaire for users of the site. The questionnaire was live, collecting data from January - February 2019. The questionnaire collected demographic data of age and gender as well as information on the user's mental health issues. Aside from demographic information, the quantitative strand provided some insight into why they used the OMHC and how they used it. The qualitative strand consisted of open-ended questions to explore in more depth how and why participants used the community and the benefits they felt they gained through using it. The open-ended questions where; "Why do you use 18percent?", "How has 18percent been useful?", "How much has the community helped you?" and "What could be done better on 18percent?" This ensured that each participant was asked the same question but had the freedom to answer subjectively (Guion, Diehl \& McDonald, 2001).

\section{Procedure}

All 128 users completed the qualitative and quantitative aspects of questionnaire via the 18percent chatrooms. An email was sent by the owners of 18percent to all active users via an e-newsletter, asking them to participate in the study. Within the email, participants were informed of the nature of the study and the collaboration between the university and 18percent so that they could make an informed decision regarding participation.

\section{Data Analysis}

The quantitative results are reported, followed by the thematic coding of the qualitative results. The qualitative data provides broad themes related to use and benefits of the OMHC, whereas the quantitative provides a more hierarchical approach to use and benefits. A multi method design allowed us to obtain different but complementary data in a short space of time on the topic of OMHC use and benefits, allowing insight into OMHC's. This was viewed the 
best method to get a general insight into the user's perspective of the OMHC since it was a short survey of reasons for, and benefits of, usage and allowed users to express their personal narrative via open ended questions.

\section{Ethics}

This study was given ethical approval by the University of Bolton's ethics board in December 2018. All participants have given their consent for their data to be used in research.

\section{Findings}

\section{Quantitative}

Table 1 shows the prevalence of self-reported mental health issues. The table represents the participant's personal perspective of their mental health issues which may or may not have been formally diagnosed by a health professional. All categories where $n<5$ were omitted form the table so as not to compromise the anonymity of participants. As evidenced below, Depressive Disorder and Anxiety disorder were the two most prevalent mental health issues.

Table 1. Self-Reported Mental Health Issues (N (\%))

\begin{tabular}{lll}
\hline Mental Health Issue & N (of participants) & Percentage (of sample) \\
\hline Depressive Disorder & 87 & $68 \%$ \\
Anxiety Disorder & 76 & $59.4 \%$ \\
Post-Traumatic Stress Disorder & 35 & $27.3 \%$ \\
Mood Disorder & 32 & $25 \%$ \\
Eating Disorder & 31 & $24.2 \%$ \\
Stress Response & 16 & $12.5 \%$ \\
Disassociation Disorder & 15 & $11.7 \%$ \\
Addiction & 14 & $10.9 \%$ \\
Impulse Control & 13 & $10.2 \%$ \\
Personality Disorder & 12 & $9.4 \%$ \\
Obsessive Compulsive Disorder & 11 & $8.6 \%$ \\
Psychosis & 10 & $7.8 \%$ \\
Sexual & 9 & $7 \%$ \\
\hline
\end{tabular}

Table 2 explores the prevalence of the reported mental health issues in relation to gender and age groups.

Table 2: Self-Reported Mental Health Issues with gender and Age (N (\% within gender and age groups)

\begin{tabular}{llllllllll}
\hline Mental Health & \multicolumn{3}{c}{ Gender } & \multicolumn{1}{c}{ Age } \\
\cline { 1 - 1 } & $\underline{\mathrm{M}}$ & $\underline{\mathrm{F}}$ & $\underline{\mathrm{Non} \mathrm{B}}$ & $\underline{4}$ & $\underline{16-24}$ & $\underline{25-35}$ & $\underline{36-46}$ & $\underline{47-57}$ & $\frac{257}{3}$ \\
Depressive Disorder & 20 & 63 & 4 & 9 & 35 & 24 & 7 & 9 & 3 \\
& $(57.1)$ & $(72.4)$ & $(66.7)$ & $(81.8)$ & $(68.6)$ & $(64.9)$ & $(70.0)$ & $(69.2)$ & $(50.0)$ \\
Anxiety Disorder & 18 & 54 & 4 & 9 & 34 & 21 & 5 & 5 & 2 \\
& $(51.4)$ & $(62.1)$ & $(66.7)$ & $(81.8)$ & $(66.7)$ & $(56.8)$ & $(50.0)$ & $(38.5)$ & $(33.3)$ \\
PTSD & 5 & 27 & 3 & 4 & 14 & 10 & 4 & 1 & 2 \\
& $(14.3)$ & $(31.0)$ & $(50.0)$ & $(36.4)$ & $(27.5)$ & $(27.0)$ & $(40.0)$ & $(7.7)$ & $(33.3)$ \\
Mood Disorder & 5 & 25 & 2 & 1 & 13 & 13 & 2 & 2 & 1 \\
& $(14.3)$ & $(71.4)$ & $(33.3)$ & $(9.1)$ & $(25.5)$ & $(35.1)$ & $(20.0)$ & $(15.4)$ & $(16.7)$
\end{tabular}




\begin{tabular}{llllllllll} 
Eating Disorder & 1 & 27 & 3 & 5 & 16 & 5 & 3 & 1 & 1 \\
& $(2.9)$ & $(31.0)$ & $(50.0)$ & $(45.5)$ & $(31.4)$ & $(13.5)$ & $(30.0)$ & $(7.7)$ & $(16.7)$ \\
Stress Response & 7 & 9 & 0 & 3 & 9 & 3 & 0 & 1 & 0 \\
& $(20.0)$ & $(10.3)$ & $(0.0)$ & $(27.3)$ & $(17.6)$ & $(8.1)$ & $(0.0)$ & $(7.7)$ & $(0.0)$ \\
Disassociation & 3 & 10 & 2 & 4 & 6 & 2 & 1 & 1 & 1 \\
& $(8.6)$ & $(11.5)$ & $(33.3)$ & $(36.4)$ & $(11.8)$ & $(5.4)$ & $(10.0)$ & $(7.7)$ & $(16.7)$ \\
Addiction & 6 & 7 & 1 & 0 & 8 & 4 & 0 & 1 & 1 \\
& $(17.1)$ & $(8.0)$ & $(16.7)$ & $(0.0)$ & $(15.7)$ & $(10.8)$ & $(0.0)$ & $(7.7)$ & $(16.7)$ \\
Impulse Control & 7 & 5 & 1 & 3 & 5 & 4 & 0 & 1 & 0 \\
& $(20.0)$ & $(5.7)$ & $(16.7)$ & $(27.3)$ & $(9.8)$ & $(10.8)$ & $(0.0)$ & $(7.7)$ & $(0.0)$ \\
Personality Disorder & 1 & 10 & 1 & 2 & 4 & 5 & 1 & 0 & 0 \\
& $(2.9)$ & $(11.5)$ & $(16.7)$ & $(18.2)$ & $(7.8)$ & $(13.5)$ & $(10.0)$ & $(0.0)$ & $(0.0)$ \\
OCD & 2 & 7 & 2 & 2 & 5 & 4 & 0 & 0 & 0 \\
& $(5.7)$ & $(8.0)$ & $(33.3)$ & $(18.2)$ & $(9.8)$ & $(10.8)$ & $(0.0)$ & $(0.0)$ & $(0.0)$ \\
Psychosis & 4 & 5 & 1 & 1 & 3 & 4 & 1 & 0 & 1 \\
& $(11.4)$ & $(5.7)$ & $(16.7)$ & $(9.1)$ & $(5.9)$ & $(10.8)$ & $(10.0)$ & $(0.0)$ & $(16.7)$ \\
Sexual & 2 & 6 & 1 & 1 & 5 & 2 & 0 & 1 & 0 \\
& $(5.7)$ & $(6.9)$ & $(16.7)$ & $(9.1)$ & $(9.8)$ & $(5.4)$ & $(0.0)$ & $(7.7)$ & $(0.0)$ \\
\hline
\end{tabular}

Table 2 shows that, of the participant group, females were more likely to experience mental health issues such as; depressive disorder, anxiety, PTSD, mood disorder, eating disorders, disassociation, personality disorder OCD and sexual disorders. However, males appeared to present more frequently with stress response and impulse control issues. The non-binary cohort presented more frequently with depressive disorder and anxiety than with other mental health issues.

Within the age ranges of 47-57 and >57, over a third of participants disclosed depressive disorder and anxiety. All the other age groups reported high percentages of depressive disorder and anxiety. This suggests that these mental health issues are most prevalent across all age ranges. The under 16 age group had a high percentage of eating disorder $(45.5 \%)$.

Participants used 18percent predominantly for emotional support $(60.2 \%, \mathrm{~N} 77)$ and peer group support (53.9\%, N 69). 42.2\% (N 54) sought advice to support their self, whilst 7.8\% $(\mathrm{N} 10)$ sought advice to support their friends and family members (5.5\%, N 7). Almost half of participants sought to hear the experience of others $(43.8 \%, \mathrm{~N} 56)$ and $32 \%(\mathrm{~N} 41)$ of participants used 18percent as a platform to share their personal experiences with others. Over half of the participants used 18percent to feel less alone $(57.8 \%, \mathrm{~N} 74)$ and $40.6 \%(\mathrm{~N}$ $52)$ used it to feel part of a community. Over a third of participants $(36.7 \%, \mathrm{~N} 47)$ used 18percent as a platform to gain knowledge regarding mental health. Table 3 suggests that over half of all gender types utilised the 18percent website for peer support; male N 18 
(51.4\%), female $\mathrm{N} 48$ (55.2\% and non-binary N 3 (50\%). This was also true for emotional support; male N 20 (57.1\%), female N 54 (62.1\%) and non-binary N 3 (50\%).

Table 3. usage of the OMHC gender and Age (N (\% within gender and age groups)

\begin{tabular}{|c|c|c|c|c|c|c|c|c|c|}
\hline \multirow[t]{2}{*}{ Usage } & \multicolumn{3}{|c|}{ Gender } & \multicolumn{6}{|c|}{ Age } \\
\hline & $\underline{\mathrm{M}}$ & $\underline{F}$ & Non B & $\leq 16$ & $16-24$ & $25-35$ & $\underline{36-46}$ & $\underline{47-57}$ & $>57$ \\
\hline Peer Support & $\begin{array}{l}18 \\
(51.4)\end{array}$ & $\begin{array}{l}48 \\
(55.2)\end{array}$ & $\begin{array}{l}3 \\
(50.0)\end{array}$ & $\begin{array}{l}6 \\
(54.5)\end{array}$ & $\begin{array}{l}32 \\
(62.7)\end{array}$ & $\begin{array}{l}20 \\
(54.1)\end{array}$ & $\begin{array}{l}5 \\
(50.0)\end{array}$ & $\begin{array}{l}5 \\
(38.5)\end{array}$ & $\begin{array}{l}1 \\
(16.7)\end{array}$ \\
\hline Emotional Support & $\begin{array}{l}20 \\
(57.1)\end{array}$ & $\begin{array}{l}54 \\
(62.1)\end{array}$ & $\begin{array}{l}3 \\
(50.0)\end{array}$ & $\begin{array}{l}8 \\
(72.7)\end{array}$ & $\begin{array}{l}35 \\
(68.6)\end{array}$ & $\begin{array}{l}22 \\
(59.5)\end{array}$ & $\begin{array}{l}5 \\
(50.0)\end{array}$ & $\begin{array}{l}5 \\
(38.5)\end{array}$ & $\begin{array}{l}2 \\
(33.3)\end{array}$ \\
\hline $\begin{array}{l}\text { Advice to Support } \\
\text { Self }\end{array}$ & $\begin{array}{l}13 \\
(37.1)\end{array}$ & $\begin{array}{l}38 \\
(43.7)\end{array}$ & $\begin{array}{l}3 \\
(50.0)\end{array}$ & $\begin{array}{l}6 \\
(54.5)\end{array}$ & $\begin{array}{l}20 \\
(39.3)\end{array}$ & $\begin{array}{l}18 \\
(48.6)\end{array}$ & $\begin{array}{l}3 \\
(30.0)\end{array}$ & $\begin{array}{l}6 \\
(46.2)\end{array}$ & $\begin{array}{l}1 \\
(16.7)\end{array}$ \\
\hline $\begin{array}{l}\text { Advice to Support } \\
\text { Family Member }\end{array}$ & $\begin{array}{l}1 \\
(29)\end{array}$ & $\begin{array}{l}6 \\
(69)\end{array}$ & $\begin{array}{l}0 \\
(0.0)\end{array}$ & $\begin{array}{l}0 \\
(0\end{array}$ & $\begin{array}{l}4 \\
(78)\end{array}$ & $\begin{array}{l}1 \\
(27)\end{array}$ & $\begin{array}{l}0 \\
(0,0)\end{array}$ & $\begin{array}{l}2 \\
(154)\end{array}$ & $\begin{array}{l}0 \\
(0,0)\end{array}$ \\
\hline Advice to Support & 2 & 8 & 0 & 0 & 6 & 3 & 0 & 0 & $1.0)$ \\
\hline Friend & (5.7) & $(9.2)$ & $(0.0)$ & $(0.0)$ & (11.8) & $(8.1)$ & $(0.0)$ & $(0.0)$ & $(16.7)$ \\
\hline Share E & $\begin{array}{l}10 \\
(28.6)\end{array}$ & $\begin{array}{l}28 \\
(32.2)\end{array}$ & $\begin{array}{l}3 \\
(50.0)\end{array}$ & $\begin{array}{l}5 \\
(45.5)\end{array}$ & $\begin{array}{l}15 \\
(29.4)\end{array}$ & $\begin{array}{l}14 \\
(37.8)\end{array}$ & $\begin{array}{l}3 \\
(30 .)\end{array}$ & $\begin{array}{l}2 \\
(15.4)\end{array}$ & $\begin{array}{l}2 \\
(33.3)\end{array}$ \\
\hline Hear Others & 13 & 42 & 1 & 5 & 20 & 20 & 5 & 3 & 3 \\
\hline Exper & (37.1) & $(48.3)$ & (16.7) & (45.5) & (39.2) & (54.1) & (50.0) & (23.1) & $(50.0)$ \\
\hline Gain Mental Health & 9 & 36 & 2 & 3 & 18 & 18 & 3 & 3 & 2 \\
\hline Know & $(25.7)$ & $(41.4)$ & $(33.3)$ & $(27.3)$ & $(35.3)$ & $(48.6)$ & $(30.0)$ & $(23.1)$ & $(33.3)$ \\
\hline Alone & $\begin{array}{l}18 \\
(51.4)\end{array}$ & $\begin{array}{l}52 \\
(59.8)\end{array}$ & $\begin{array}{l}4 \\
(66.7)\end{array}$ & $\begin{array}{l}7 \\
(63.6)\end{array}$ & $\begin{array}{l}34 \\
(66.7)\end{array}$ & $\begin{array}{l}22 \\
(59.5)\end{array}$ & $\begin{array}{l}6 \\
(60.0)\end{array}$ & $\begin{array}{l}5 \\
(38.5)\end{array}$ & $\begin{array}{l}0 \\
(0.0)\end{array}$ \\
\hline $\begin{array}{l}\text { Feel Part of the } \\
\text { Community }\end{array}$ & $\begin{array}{l}16 \\
(45.7)\end{array}$ & $\begin{array}{l}33 \\
(37.9)\end{array}$ & $\begin{array}{l}3 \\
(50.0)\end{array}$ & $\begin{array}{l}8 \\
(72.7)\end{array}$ & $\begin{array}{l}21 \\
(41.2)\end{array}$ & $\begin{array}{l}15 \\
(40.5)\end{array}$ & $\begin{array}{l}4 \\
(40.0)\end{array}$ & $\begin{array}{l}3 \\
(23.1)\end{array}$ & $\begin{array}{l}1 \\
(16.7)\end{array}$ \\
\hline Other & $\begin{array}{l}1 \\
(2.9)\end{array}$ & $\begin{array}{l}1 \\
(1.1)\end{array}$ & $\begin{array}{l}0 \\
(0.0)\end{array}$ & $\begin{array}{l}0 \\
(0.0)\end{array}$ & $\begin{array}{l}1 \\
(2.0)\end{array}$ & $\begin{array}{l}1 \\
(2.7)\end{array}$ & $\begin{array}{l}0 \\
(0.0) \\
\end{array}$ & $\begin{array}{l}0 \\
(0.0)\end{array}$ & $\begin{array}{l}0 \\
(0.0)\end{array}$ \\
\hline
\end{tabular}

\section{Qualitative}

To ascertain and increase intercoder reliability, all three authors read the raw qualitative data, ensuring the eradication of single researcher bias and improving the trustworthiness of the analysis and conclusions drawn. Following the six recursive phases set out by Braun \& Clarke (2012, 2019), thematic analysis was used to analyse the qualitative data set. All authors then reviewed themes and discussed the data at length to refine the themes and subthemes. This refining process demonstrates the overall reliability of the data analysis process. This was achievable as the data set was relatively small and based on open ended responses from a quantitative online questionnaire.

Primarily, data was coded into participants experience; Online Belonging and Support Seeking and Transition to Further Support. These then became the overarching themes when reflecting on the research objectives. Next, subthemes were identified, reviewed, concisely defined and agreed upon and reported by all authors. 


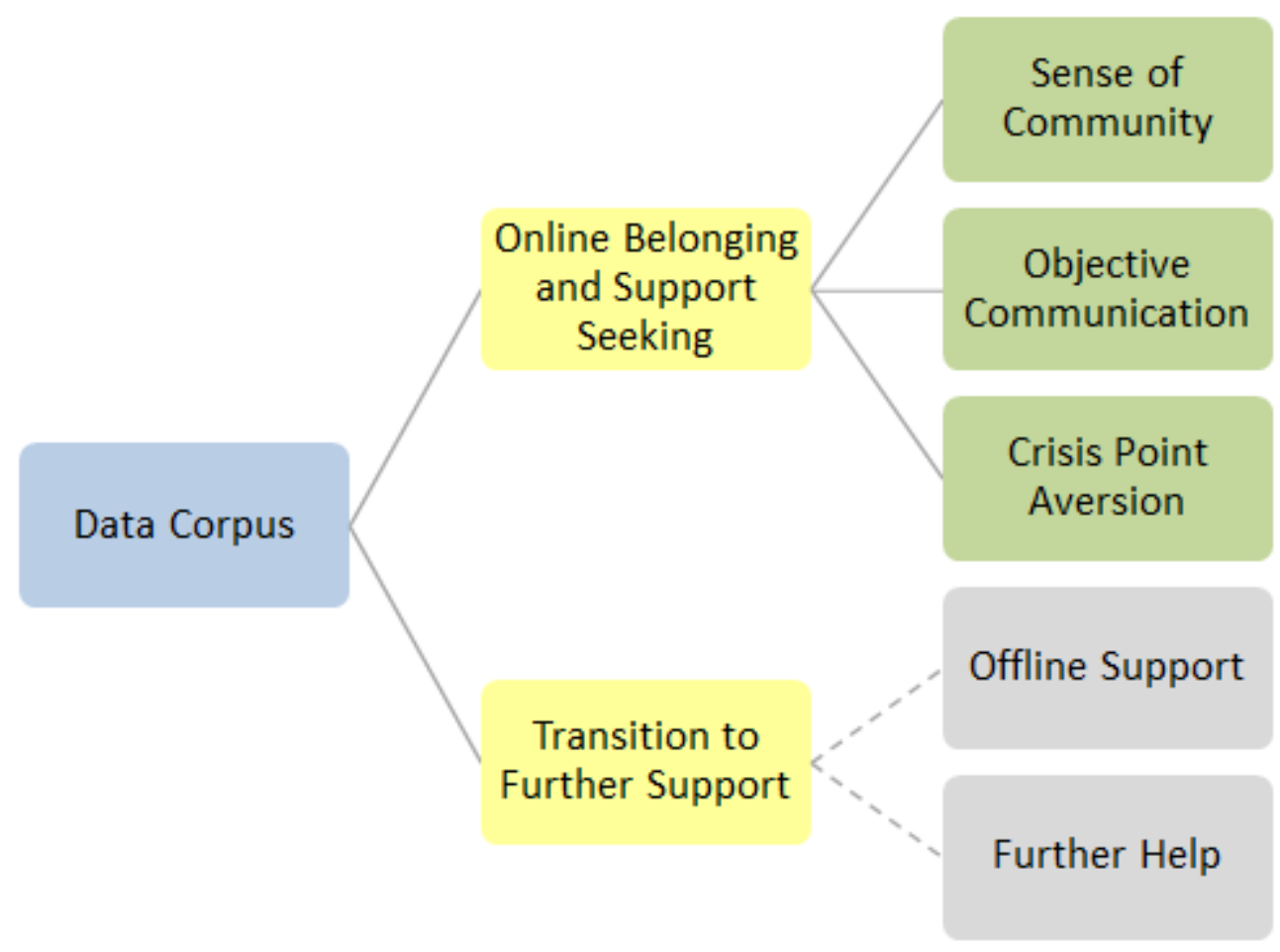

Figure 1. Thematic Map

Figure 1 presents the initial thematic map devised by the authors. As evidenced in the figure, the data corpus is presented in blue, the themes are yellow, and subthemes are green/grey. The two subthemes initially thought to be present in the theme Transition to Further Support were coded grey with a broken line as authors were unsure whether these subthemes were too alike be separated under two different subthemes. Due to this uncertainty, the data from this theme were reviewed again and responses were compared.

It was decided by the authors that the two subthemes, Offline Support and Further Help were topically similar in the sense that any quotes which was coded here, all related to transitioning to further support offline. Due to the parallel connotations, authors decided that the subthemes within Transition to Further Support could not be justified, and the thematic map was revised leaving no subthemes for this theme (Figure 2). 


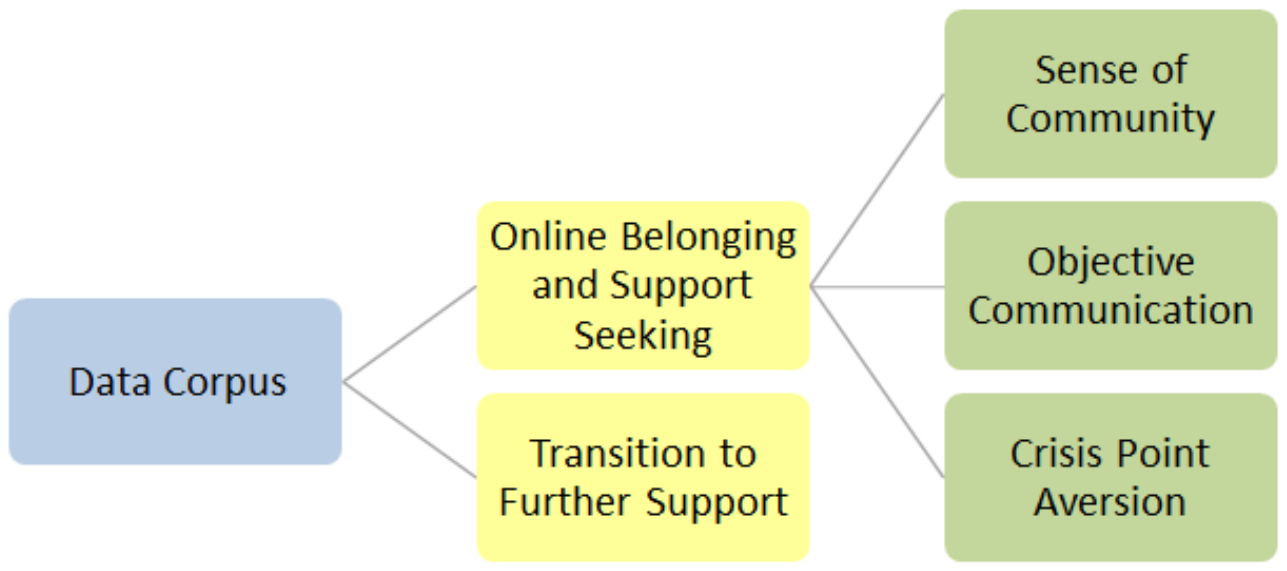

Figure 2. Revised Thematic Map

The final themes and subthemes are presented alongside representative quotes from users in table 4.

Table 4. Themes, Subthemes and Representative Quotes

\begin{tabular}{|c|c|c|}
\hline Themes & Subthemes & (Participants) Representative quote \\
\hline \multirow[t]{3}{*}{$\begin{array}{l}\text { Online Belonging } \\
\text { and Support Seeking }\end{array}$} & Sense of Community & $\begin{array}{l}\text { 18percent has been very useful. I no } \\
\text { longer feel alone in anything, I } \\
\text { actually feel like I am a part of } \\
\text { something where I belong. I'm } \\
\text { extremely thankful I've joined } \\
\text { (Participant 55, Female, Aged 16- } \\
\text { 24). }\end{array}$ \\
\hline & Objective Communication & $\begin{array}{l}\text { I was able to talk to people not } \\
\text { connected to my problems not just } \\
\text { about my problems but about } \\
\text { anything, helping me see more } \\
\text { clearly (Participant 22, Male, Aged } \\
\text { 16-24). }\end{array}$ \\
\hline & Crisis Point Aversion & $\begin{array}{l}\text { It has helped me when I was really } \\
\text { freaking out and couldn't calm } \\
\text { down, the people on there are } \\
\text { usually so supportive. It helps when } \\
\text { I go down a thought spiral and my } \\
\text { compulsions and crazy (Participant } \\
66, \text { Female, under 16) }\end{array}$ \\
\hline $\begin{array}{l}\text { Transition to Further } \\
\text { Support }\end{array}$ & & $\begin{array}{l}\text { I'm very grateful I found } 18 \text { percent } \\
\text { and have gotten better and started a }\end{array}$ \\
\hline
\end{tabular}


track to recovery. I've dropped toxic friends, gotten a new therapist, and headed in the right directions (Participant 19, Non-Binary, aged 16-24)

\section{Online Belonging and Support Seeking}

The theme of online belonging and support seeking consisted of three subthemes; sense of community, objective communication and crisis point aversion. The overall theme shows why users turn to online mental health communities when they are experiencing problems with their mental health.

\section{Sense of Community}

Users of the OMHC perceived it to be an online space where they could become part of a community and communicate with likeminded people. This sense of community allowed users to feel less isolated and alone and allowed for the sharing of experiences. For example, the following quote highlights how sharing experiences and stories can facilitate in support and helping, either receiving help or providing help. The quote also indicates the nuances of online support;

I've had individual conversations with people with similar struggles. Sometimes I help them, sometimes they help me, sometimes we just empathize (which seems to help both of us) (Participant 100, Male, Aged 47-57).

\section{Objective Communication}

The OMHC allowed users to communicate with individuals/peers who may not only experience the same issues and symptomology as themselves, but also people who were objective to their situation and were able to offer impartial advice.

There have been many people $i$ have reached out to in a personal message and it has really helped me feel less alone and less "stupid". There are some very sensitive topics that I cannot discuss with any of my family or friends and I have felt safe and comfortable discussing them with peers on 18percent (Participant 69, Female, Aged 25-35).

Users may not feel able to discuss their mental health with the people closest to them offline for fear of upsetting them, becoming a burden or experiencing a negative, stigmatised response following disclosure. Due to such reasons, the anonymity provided by the OMHC can make users feel more comfortable turning to the online platform. It can be helpful for people to discuss their experiences and coping mechanisms with others due to the subjectivity of mental health issues. The anonymity of the online environment offers a space for increased self-disclosure, an important affordance of the online environment, especially for more sensitive issues.

\section{Crisis Point Aversion}

One crucial reason within this study as to why users utilised the online OMHC was crisis point aversion. Participants utilised the chat room when they considered their self to be 
nearing or experiencing a crisis point. This suggests that participants were able to recognise when their mental health was deteriorating and access the site with the intentions to alleviate the severity of their thoughts, feelings and behaviours. Similarly, for some users, the mental health community played a vital part in relieving thoughts of suicide; Helps me to live when I don't to (Participant 12, Male, aged 16-24).

\section{Transition to further support}

The theme, transition to further support, shows how the use of the OMHC could lead users to access further mental health care on or offline. From the data it was evident that users gained increasing awareness and, in some cases, confidence around mental health and seeking support as well as the ability to be emphatic towards others. This support, we have termed 'transitional support', provides further evidence of the value of online mental health support, which for some users, goes beyond peer-to-peer support and online community involvement.

The OMHC provides a platform where users can discuss and ruminate over the actions they take on the online platform in order to manage their mental health. It was evident that for some participants joining the community had enabled them to become more proactive in receiving support for their mental health. For instance, the quote presented in table 2 suggests that 18percent was vital in the users' road to recovery, aiding the participant to put a recovery plan in place by altering their social circle and professional support. Other users found the community helped them seek further support and the OMHC was used as a signposting tool.

\section{Convergence of quantitative and qualitative data}

The qualitative data generated a broad theme of support and belonging related to why participants used the OMHC. This was then sub-themed into more specifically, objective communication, suggesting that it is the ability to receive objective feedback that helps support users and sense of community. The sense of community sub-theme may appear at first as an obvious reason for the use. However, this sense of the community is important online, and it is not guaranteed. The non-professional moderators of the site go a long way in providing this for the 18percent OMHC. The role of the moderators in the context is to provide a safe environment for users, making sure that users are using the site to support and not put other users in any danger. Moderation is a paramount function of the site since crisis point aversion was also emphasised as an important aspect of the site. Often users turned to the site when they had reached a crisis point, suggesting the OMHC played a vital role in immediate, perhaps short-term support for users at that point. The crisis point aversion leads into the following theme of transition to further support. This is a significant benefit of the site.

The support and community elements are also clear from the quantitative data. From the quantitative data emotional support was the most common reason for the use of 18percent by participants, followed closely by peer support. The quantitative data shows that participants used the OMHC to hear about other people's experiences as well as share their own experiences, supporting previous finds from research conducted on professionally moderated 
sites (Prescott et al, 2017, 2019). 18percent serves a function for mental health support in a similar vein as a professionally moderated online environment. This was evident from the quantitative and qualitative strands of data. Users benefit from using the site in terms of decreasing feelings of loneliness, community belonging and gained information on mental illness. This is a repeated benefit of the online environment throughout the research and is specific to online communities since they are available 24/7.

\section{Discussion}

From this study it was found that most users turned to the OMHC for both emotional and informational support from a likeminded, non-bias peer group. Users perceived the OMHC to be an online space where they could become part of a safe, inclusive, communal space. 18percent was predominantly used to support one's own mental health and emotional needs. This research supports previous findings which suggest that online OMHCs are beneficial to users as they provide a sense of community which can potentially eradicate feelings of loneliness for those with mental health issues and offer a third party to converse with, who can offer impartial advice, guidance and support. This appeared to encourage disclosure to others, and even allows the user to reframe their own situation, perceiving it from a different angle. This supports previous research which suggests communicating with other individuals online can not only decreases loneliness but also increases perceived social support (Shaw \& Gant, 2004). The online OMHC allowed users to communicate with individuals who may, not only experience the same issues and symptomology as their self, but also, people who were objective to their situation and are able to offer impartial advice (Sillence, 2017).

Underpinned by increased and positive communication, OMHC's have the propensity to increase self-efficacy in those with mental health issues, subsequently resulting in a transition to further support. Mastery of experiences was evidenced in several ways throughout the data. Primarily, joining the OMHC then communicating with other users, and finally holding private conversations are all behaviours which evidence incremental phased but increasing engagement. Disclosing personal information to other users in itself is a form of mastery as the discourse becomes more and more in depth and other users begin to offer suggestions for coping mechanisms or treatments.

Social modelling occurred when users participated in knowledge transfer with each other, offering solutions to any presented problems or even just a listening ear. Users of the OMHC benefitted from sharing experiences with others. People who had made alteration in their lives and been proactive within their mental health engaged in pro-social behaviour, encouraging others to do the same. Verbal/social persuasion is shown through the encouragement evident throughout the site, providing a space of belonging and minimising feelings of loneliness resulting in increased confidence and leading to change. It is important to know that users can autonomously recognise when they are reaching a crisis point in regard to their mental health and utilise the OMHC to avert a crisis situation.

Although users are turning to the OMHC to become active participants within their wellbeing and to regulate their own mental health in times of need, it is apparent that there is still a need 
for a more advanced level of support for some users than can be facilitated by this online community. Discussing mental health experiences with those who may have similar experiences can bring a sense of reassurance (Powell \& Clarke, 2006; Prescott and Mackie, 2017). This type of communication is effective as it prompts users understanding of shared experiences, and subsequently, a greater sense of control regarding managing their situation can be granted (Ziebland \& Wyke, 2012). One salient behavioural aspect of self-efficacy, improving physical and emotional states, can be seen when user's turn to the OMHC when they autonomously identify that they have reached a crisis point and may consider or engage in self-harm. Below is a suggested theoretical framework devised by the authors for maintaining and increasing levels of self-efficacy when communication online for one's mental health.

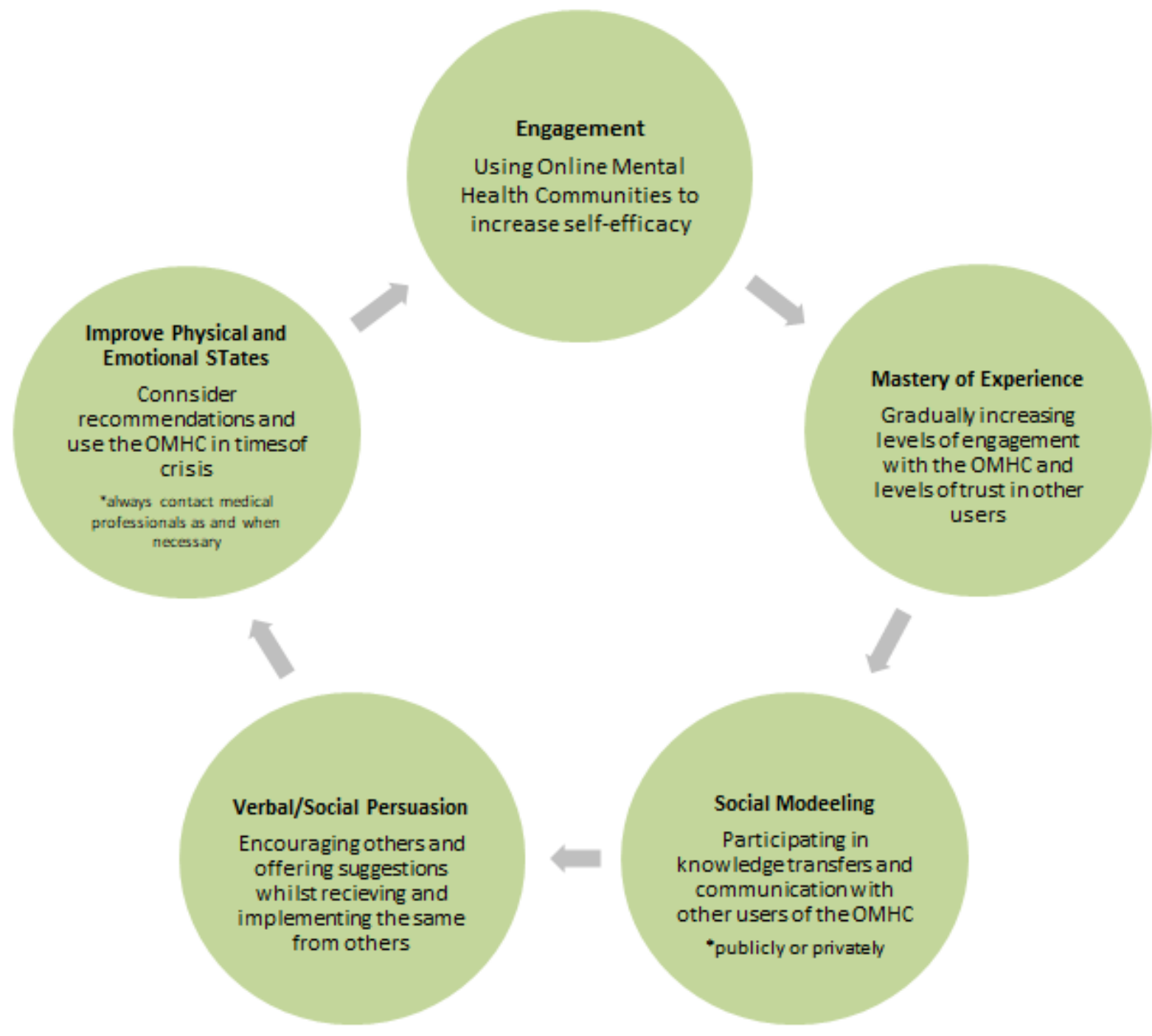

Figure 3. Promoting Self Efficacy in Online Mental Health Communities 
Although not originally an aim of the research and not a theme as such, the moderation of the site was mentioned throughout the qualitative data. The platform was often referred to as a 'safe and comfortable' environment. It is this safety that is important for an online mental health space to provide. The moderators on the site, although non-professional, play an important role in providing this 'safe space'. It was clear that the users of 18percent were grateful of the presence of the moderator role on the platform. So much so, that when the users were asked how 18percent may be improved, increasing the number, and presence, of moderators was repeatedly suggested. The chat rooms on the OMHC are specific to mental health illnesses and users can converse in each and any chat room deemed relevant (e.g. anxiety, eating disorder, PTSD, etc). Some users prefer that each chat room is constantly and consistently moderated. This suggests that whilst some users may initially aim to independently manage their mental health issues using the online mental health community, they may still require further assistance. However, as the role is on a voluntary basis, this is not always feasible. This can lead the user to feel that the moderation provided is not adequate and subsequently, highlights a vital feature for future development of OMHCs. Increased moderator presence was especially sought during unsociable hours; perhaps due to offline support services being closed, or indeed after the user themselves have the time after work, more people turned to the online platform for support.

\section{Limitations}

One limitation of the cross-sectional research is that it is conducted on a relatively small sample of self-selected participants via an online questionnaire. In parts, the qualitative data was limited by both the online format for returned responses and contextual depths proffered by participants. Often responses were limited to one or two sentences long, subsequently restricting data interpretation. Additionally, the data collated from the study originated from a singular online mental health community. Participants within this study were not asked whether they had received a formal diagnosis from a professional or whether their symptoms were self-diagnosed, information which would benefit the findings.

\section{Further Research}

The authors posit that further research should focus on specifically how the transition from online to offline support and help seeking is facilitated by OMHCs and instigated by users, and also explore levels of self-efficacy using a quantitative method so a larger data set can be achieved and the results may be deemed generalizable.

Transition to further support should be further explored to gain a better understanding of how effective transitional support from peer-to-peer communities to professional support can be established. User differences and the subjective need for varying levels of support should be considered in further research. For example, some users may deem the informational and emotional support from OMHCs to be enough when meeting their support needs. Other users may seek the same informational and emotional support from OMHCs yet find their selves more dependent on the moderators of the community. Most moderators are in nonprofessional, volunteer roles and future research should explore the motivation for volunteering and whether the role affects their own mental health, whether positively or negatively. There are also users who find that, utilising an OMHC may lead them to seek 
further help from professionals, whether online or offline. The transitional support provided by the OMHC should be further explored by future research, so organisations find themselves better equipped to redirect users when necessary.

\section{Conclusion}

Users gained emotional and informational support through peer communication and support. Underpinned by increased and positive communication, OMHC's can increase self-efficacy, resulting in a transition to further support when required. Applying a social cognitive theory framework enables an insight into how users of 18percent use the OMHC and how they can benefit from the OMHC through increased self-efficacy.

\section{Recommendations}

From this research, it is evident that OMHCs are beneficial for those with mental health issues. OMHCs should be recommended to those in need of support when they are waiting to be referred to offline support. OMHCs are also suitable for continuous peer-to-peer support. Although this study has evidenced that OMHCs can be useful for crisis aversion, it is salient that mental health care professionals continue to reiterate to patients that OMHCs cannot be relied upon solely for mental health care for those needing additional support.

\section{Acknowledges}

The authors would like to thank the University of Bolton's Jenkinson Award for funding this research, the co-founders of 18percent for their input and support and the users who completed the online survey for this research.

\section{References}

Cherry, S. (2017). Transforming behaviour: Pro-social modelling in practice. Taylor \& Francis.

Naslund, J. A., Aschbrenner, K. A., Marsch, L. A., \& Bartels, S. J. (2016). The future of mental health care: peer-to-peer support and social media. Epidemiology and psychiatric sciences, 25(2), 113-122.

Isaac, V., Wu, C. Y., McLachlan, C. S., \& Lee, M. B. (2018). Associations between healthrelated self-efficacy and suicidality. BMC psychiatry, 18(1), 1-8.

18percent. (2019). About Us - 18percent. Retrieved from https://18percent.org/about/

Bandura, A. (1988). Self-efficacy conception of anxiety. Anxiety research, 1(2), 77-98.

Braun, V. \& Clarke, V. (2012). Thematic analysis. In H. Cooper, P. M. Camic, D. L. Long, A. T. Panter, D. Rindskopf, \& K. J. Sher (Eds.), APA handbook of research methods in psychology, Vol. 2: Research designs: Quantitative, qualitative, neuropsychological, and biological (pp. 57-71). Washington, DC: American Psychological Association. 
Braun, V., \& Clarke, V. (2019). Reflecting on reflexive thematic analysis. Qualitative Research in Sport, Exercise and Health, 11(4), 589-597.

Bakker, D., Kazantzis, N., Rickwood, D., \& Rickard, N. (2016). Mental health smartphone apps: review and evidence-based recommendations for future developments. JMIR mental health, 3(1), e7.

Barak, A. (2007). Emotional support and suicide prevention through the Internet: A field project report. Computers in Human Behavior, 23(2), 971-984.

doi:10.1016/j.chb.2005.08.001

Bruckman, A. S., Below, J. E., Dixon, L., Fiesler, C., Gilbert, E. E., Gilbert, S. A., \& Matias, J. N. (2018, April). Managing Deviant Behavior in Online Communities III. In Extended Abstracts of the 2018 CHI Conference on Human Factors in Computing Systems (p. panel02). ACM.

Creswell, J. W., Plano Clark, V. L., Gutmann, M. L., \& Hanson, W. E. (2003). Advanced mixed methods research designs. Handbook of mixed methods in social and behavioral research, 209, 240.

De Choudhury, M., \& De, S. (2014, May). Mental health discourse on reddit: Self-disclosure, social support, and anonymity. In Eighth International AAAI Conference on Weblogs and Social Media.

Doran, C. M., \& Kinchin, I. (2019). A review of the economic impact of mental illness. Australian Health Review, 43(1), 43-48.

Fortuna, K. L., Brooks, J. M., Umucu, E., Walker, R., \& Chow, P. I. (2019). Peer support: a human factor to enhance engagement in digital health behavior change interventions. Journal of Technology in Behavioral Science, 1-10.

Fox, S., \& Duggan, M. (2013). Health online 2013. Health, 2013, 1-55.

Gilat, I., \& Shahar, G. (2007). Emotional first aid for a suicide crisis: comparison between Telephonic hotline and internet. Psychiatry: Interpersonal and Biological Processes, 70(1), 12-18.

Giles, D. C., \& Newbold, J. (2011). Self-and other-diagnosis in user-led mental health online communities. Qualitative Health Research, 21(3), 419-428.

Gray, N. J., McDonagh, J. E., Prescott, J., Smith, F. J., Harvey, K., Shaw, K. L., \& Terry, D. (2014). Arthriting-Insights about the links between identity, arthritis and medication in the blogs of young people living with juvenile arthritis. Journal of Adolescent Health, 54(2), S18.

Guion, L. A., Diehl, D. C., \& McDonald, D. (2001). Conducting an in-depth interview. McCarty Hall, FL: University of Florida Cooperative Extension Service, Institute of Food and Agricultural Sciences, EDIS. 
Jacobs, W., Amuta, A. O., \& Jeon, K. C. (2017). Health information seeking in the digital age: An analysis of health information seeking behavior among US adults. Cogent Social Sciences, 3(1), 1302785.

Johnson, A., Potter, K., \& Bishop, E. (2019, March). Exploring Asynchronous Online Learner Experiences and Perceptions. In Society for Information Technology \& Teacher Education International Conference (pp. 466-472). Association for the Advancement of Computing in Education (AACE).

Kallestad, H., Langsrud, K., Vedaa, Ø., Stiles, T., Vethe, D., Lydersen, S., ... \& Sivertsen, B. (2018). 0371 A randomized noninferiority trial comparing cognitive behavior therapy for insomnia (cbt-i) delivered by a therapist or via a fully automated online treatment program. Sleep, 41(suppl_1), A142-A142.

Karyotaki, E., Kemmeren, L., Riper, H., Twisk, J., Hoogendoorn, A., Kleiboer, A., ... \& Littlewood, E. (2018). Is self-guided internet-based cognitive behavioural therapy (iCBT) harmful? An individual participant data meta-analysis. Psychological medicine, 48(15), 24562466.

Kiyimba, N., Lester, J. N., \& O’Reilly, M. (2019). Utilising Computer-Mediated Communication and the Internet in Health Research. In Using Naturally Occurring Data in Qualitative Health Research (pp. 179-203). Springer, Cham.

Liu, Y., Kornfield, R., Shaw, B. R., Shah, D. V., McTavish, F., \& Gustafson, D. H. (2017). When support is needed: Social support solicitation and provision in an online alcohol use disorder forum. Digital health, 3, 2055207617704274.

March, S., Day, J., Ritchie, G., Rowe, A., Gough, J., Hall, T., ... \& Ireland, M. (2018). Attitudes toward e-mental health services in a community sample of adults: online survey. Journal of medical Internet research, 20(2), e59.

McCosker, A. (2018). Engaging mental health online: Insights from beyond blue's forum influencers. New Media \& Society, 20(12), 4748-4764.

McAlister, A. L., Perry, C. L., \& Parcel, G. S. (2008). How individuals, environments, and health behaviors interact. Health Behavior, 169.

McAlister, A. L., Perry, C. L., Parcel, G. S., Glanz, K., Rimer, B. K., \& Viswanath, K. (2008). Health behavior and health education: Theory, research, and practice. How Individuals, Environments, and Health Behaviors Interact: Social Cognitive Theory.

Moore, D., \& Ayers, S. (2017). Virtual voices: social support and stigma in postnatal mental illness Internet forums. Psychology, health \& medicine, 22(5), 546-551.

Naslund, J. A., Aschbrenner, K. A., Marsch, L. A., \& Bartels, S. J. (2016). The future of mental health care: peer-to-peer support and social media. Epidemiology and psychiatric sciences, 25(2), 113-122. 
Naslund, J. A., Aschbrenner, K. A., Kim, S. J., McHugo, G. J., Unützer, J., Bartels, S. J., \& Marsch, L. A. (2017). Health behavior models for informing digital technology interventions for individuals with mental illness. Psychiatric rehabilitation journal, 40(3), 325.

Nath, C., Huh, J., Adupa, A. K., \& Jonnalagadda, S. R. (2016). Website sharing in online health communities: a descriptive analysis. Journal of medical Internet research, 18(1), e11.

Newton, J., \& Fitzpatrick, J. (2018). Health Profile for England: the health of England today and into the future - Public health matters. Retrieved from

https://publichealthmatters.blog.gov.uk/2018/09/11/health-profile-for-england-the-health-ofengland-today-and-into-the-future/

NHS. (2018). Depression support groups. Retrieved from https://www.nhs.uk/conditions/stress-anxiety-depression/depression-help-groups/

NHS. (2019). Kooth - Healthy Young Minds. Retrieved from https://healthyyoungmindspennine.nhs.uk/resource-centre/external-links/kooth/

Park, A., Conway, M., \& Chen, A. T. (2018). Examining thematic similarity, difference, and membership in three online mental health communities from Reddit: a text mining and visualization approach. Computers in human behavior, 78, 98-112.

Pavalanathan, U., \& De Choudhury, M. (2015, May). Identity management and mental health discourse in social media. In Proceedings of the 24th International Conference on World Wide Web (pp. 315-321).

Poulin, P. A., Romanow, H. C., Cheng, J., Liddy, C., Keely, E. J., \& Smyth, C. E. (2018). Offering eConsult to family physicians with patients on a pain clinic wait list: an outreach exercise. Journal for Healthcare Quality, 40(5), e71-e76.

Powell, J., \& Clarke, A. (2006). Internet information-seeking in mental health: population survey. The British Journal of Psychiatry, 189(3), 273-277.

Prescott, J., \& Mackie, L. (2017). "You Sort of Go Down a Rabbit Hole... You're Just Going to Keep on Searching": A Qualitative Study of Searching Online for Pregnancy-Related Information During Pregnancy. Journal of medical Internet research, 19(6), e194.

Prescott, J., Hanley, T., \& Ujhelyi Gomez, K. (2019). Why do young people use online forums for mental health and emotional support? Benefits and challenges. British Journal of Guidance \& Counselling, 1-11.

Prescott, J., Hanley, T., \& Ujhelyi, K. (2017). Peer communication in online mental health forums for young people: directional and nondirectional support. JMIR mental health, 4(3), e29.

Prestin, A., Vieux, S. N., \& Chou, W. Y. S. (2015). Is online health activity alive and well or flatlining? Findings from 10 years of the Health Information National Trends Survey. Journal of health communication, 20(7), 790-798. 
Priester, M. A., Browne, T., Iachini, A., Clone, S., DeHart, D., \& Seay, K. D. (2016).

Treatment access barriers and disparities among individuals with co-occurring mental health and substance use disorders: an integrative literature review. Journal of substance abuse treatment, 61, 47-59.

Radovic, A., Li, Y., Landsittel, D., Stein, B. D., \& Miller, E. (2019). A Social Media Website (Supporting Our Valued Adolescents) to Support Treatment Uptake for Adolescents With Depression and/or Anxiety and Their Parents: Protocol for a Pilot Randomized Controlled Trial. JMIR research protocols, 8(1), e12117.

Sane. (2019). About Us | SANE. Retrieved from

http://www.sane.org.uk/what_we_do/about_sane/

Saxena, S., Funk, M., \& Chisholm, D. (2013). World health assembly adopts comprehensive mental health action plan 2013-2020. The Lancet, 381(9882), 1970-1971.

Schaefer, J. D., Caspi, A., Belsky, D. W., Harrington, H., Houts, R., Horwood, L. J., ... \& Moffitt, T. E. (2017). Enduring mental health: prevalence and prediction. Journal of abnormal psychology, 126(2), 212.

Schlenk, E. (2018). Characteristics of Computer-Mediated Communication in Counselling and Therapy. Guidelines for Advisors, Counsellors and Therapists on the Utilization of Online Interventions.[Internet]

Shaw, L. H., \& Gant, L. M. (2004). In defence of the Internet: The relationship between Internet communication and depression, loneliness, self-esteem, and perceived social support. Internet Research, 28(3).

Sillence, E. (2017). Having faith in the online voice: Exploring contemporary issues of trust, language and advice in the context of e-health. Linguistik online, 87(8).

Steinman, K. J., Shoben, A. B., Dembe, A. E., \& Kelleher, K. J. (2015). How long do adolescents wait for psychiatry appointments?. Community mental health journal, 51(7), 782789.

Stephens, T., \& Joubert, N. (2001). The economic burden of mental health problems in Canada. Chronic diseases in Canada, 22(1), 18-23.

Trautmann, S., Rehm, J., \& Wittchen, H. U. (2016). The economic costs of mental disorders: Do our societies react appropriately to the burden of mental disorders?. EMBO reports, 17(9), 1245-1249.

Vollert, B., Beintner, I., Musiat, P., Gordon, G., Görlich, D., Nacke, B., ... \& Schmidt, U. (2019). Using internet-based self-help to bridge waiting time for face-to-face outpatient treatment for Bulimia Nervosa, Binge Eating Disorder and related disorders: Study protocol of a randomized controlled trial. Internet interventions, 16, 26-34. 
Vos, T., Barber, R. M., Bell, B., Bertozzi-Villa, A., Biryukov, S., Bolliger, I., ... \& Duan, L. (2015). Global, regional, and national incidence, prevalence, and years lived with disability for 301 acute and chronic diseases and injuries in 188 countries, 1990-2013: a systematic analysis for the Global Burden of Disease Study 2013. The Lancet, 386(9995), 743-800.

Weekly, T., Walker, N., Beck, J., Akers, S., \& Weaver, M. (2018). A review of apps for calming, relaxation, and mindfulness interventions for paediatric palliative care patients. Children, 5(2), 16.

WHO. (2001). WHO | Mental disorders affect one in four people. Retrieved from https://www.who.int/whr/2001/media_centre/press_release/en/

Wilks, C. R., Coyle, T. N., Krek, M., Lungu, A., \& Andriani, K. (2018). Suicide Ideation and Acceptability Toward Online Help-Seeking. Suicide and Life-Threatening Behavior, 48(4), 379-385.

XenZone. (2019). Kooth - XenZone | Future Thinking for Mental Health. Retrieved from https://xenzone.com/kooth/

Yang, D., Kraut, R., Smith, T., Mayfield, E., \& Jurafsky, D. (2019). Seekers, Providers, Welcomers, and Storytellers: Modeling Social Roles in Online Health Communities.

Yu, S. W. Y., Ma, A., Tsang, V. H. M., Chung, L. S. W., Leung, S. C., \& Leung, L. P. (2019). Triage accuracy of online symptom checkers for Accident and Emergency Department patients. Hong Kong Journal of Emergency Medicine, 1024907919842486.

Ziebland, S. U. E., \& Wyke, S. (2012). Health and illness in a connected world: how might sharing experiences on the internet affect people's health?. The Milbank Quarterly, 90(2), 219-249. 